\title{
Workplace smoking policy and changes in smoking behaviour in California: a suggested association
}

\author{
Christi A Patten, Elizabeth Gilpin, Shirley W Cavin, John P Pierce
}

\begin{abstract}
Objective-To examine the association between changes in smoking behaviour and changes in workplace smoking policies in California, USA.

Design-Population-based telephone survey.

Subjects-Longitudinal sample of 1844 California adult indoor workers interviewed in 1990 and 1992. Respondents were classified into one of four groups according to whether they worked in a smoke-free work area in neither 1990 nor 1992 (group 1), in 1992 only (group 2), in 1990 and in 1992 (group 3), or in 1990 only (group 4).
\end{abstract}

Main outcome measures-Changes in smoking status and cigarette consumption.

Results-Smoking prevalence changed from 1990 to 1992 as a function of change in workplace smoking policy. In group 3 there was a percentage decrease of $11.4 \%$, but only a $5.9 \%$ decrease in group 2 . For group 4, smoking prevalence showed a percentage increase of $50.9 \%$, whereas group 1 was unchanged. Although these individual effects were not statistically significant, the $\chi^{2}$ analysis for the overall change in smoking status among those who were current smokers in either 1990 or 1992 suggested there was an association $(\mathrm{p}<0.06)$. The largest decrease in cigarette consumption (1.4 cigarettes/day) was found for group 2. Group 4 increased their daily cigarette consumption by about four cigarettes per day, and $38.0 \%$ of these workers did not report smoking in 1990, but reported smoking in 1992 . Multivariate analysis indicated that those who change from working in an area under a smoke-free policy to no restrictions are highly unlikely to decrease their cigarette consumption.

Conclusion - Workplace smoking policies that are maintained may encourage changes in smoking behaviour. Smoking prevalence and cigarette consumption may increase when workers move from a workplace that prohibits smoking in the work area to one that allows work area smoking.

(Tobacco Control 1995; 4: 36-41)
Keywords: smoking restrictions; workplace; smoking behaviour, changes

\section{Introduction}

Policies restricting smoking in the workplace have increased considerably in recent years. ${ }^{1}$ Although the primary aim of these policies is to protect the non-smoker from exposure to environmental tobacco smoke (ETS), ${ }^{2}$ smoking restrictions may also benefit the health of smokers by facilitating changes in smoking behaviour ${ }^{3,4}$ A previous cross-sectional study ${ }^{5}$ found lower smoking prevalence among workers in California reporting at least a work area smoking ban compared with those with no smoking restrictions. Cigarette consumption was also lower among workers reporting more comprehensive smoking policies.

Many studies have reported that employees decrease their workday ${ }^{6-9}$ and total ${ }^{10-12}$ cigarette consumption after workplace smoking policies have been introduced. The evidence for increased rates of smoking cessation is less clear, ${ }^{10-14}$ although few studies have included a sufficient follow-up period to determine the impact of workplace smoking restrictions on prevalence. A longitudinal study conducted at Johns Hopkins Medical Center found a selfreported quit rate of $20.4 \%$ a year after a smoke-free policy was implemented. ${ }^{15}$ Thus, it is possible that smoking prevalence decreases steadily over a considerable period.

Smokers who have modified their behaviour under a workplace smoking policy may be at risk for relapse to smoking or increasing cigarette consumption when moving to a workplace with no smoking restrictions. Although this potential outcome has not been studied, some data suggest that occasional or non-daily smokers may become regular smokers in workplaces with no smoking restrictions. ${ }^{5}$

In this study, we explore the relationship between changes in smoking behaviour and various changes in workplace smoking policies in a longitudinal sample of California indoor workers.

Methods

SURVEY DESIGN AND METHODOLOGY

The data in this study are from the longitudinal
$=$

s.

$\forall=$

$+$

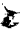

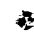

5

ses

$y$

3

2

$r$

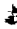

F

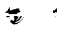

2

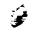

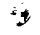

$\geq 2$ 
component of the 1992 California Tobacco Survey (CTS), a telephone survey using digits dialled at random, with sampling based on the methods of Waksberg. ${ }^{16,17}$ Between June 1990 and February 1991, the 1990 CTS contacted 42790 households and achieved a screening interview with 32125 respondents (response rate $=75.1 \%$ ). All adults (18 years of age or older) who had smoked within the last five years were scheduled for an extended interview, as were a random sample of $28 \%$ of never-smokers or those who had not smoked in the last five years. Interviews were completed for $24296(75.3 \%)$ of those scheduled.

To identify changes in smoking behaviour, selected respondents to the 1990 CTS were scheduled for a follow-up interview in 1992 (between March and July), an average of 18 months following their initial interview in 1990. The selection criteria for the follow-up interview emphasised the importance of measuring behaviour change that might be associated with different tobacco control interventions. Accordingly, we oversampled people aged 18-39 years at the 1990 interview, smokers, and those who had quit smoking within the five years before the 1990 interview. We undersampled respondents aged 40 years and older who had either never smoked or who had quit more than five years before the 1990 interview. The sampling fraction was $42 \%$ for the first three groups and $6 \%$ for the latter group. A total of 7498 respondents were selected from those meeting the criteria.

Unfortunately, fieldwork for the second interview coincided with the Los Angeles riots of 1992 and the resulting disruption affected survey responses. ${ }^{18}$ One month before the end of the field period, we added another 1812 respondents to the sampling frame. Overall, 9310 respondents were selected, of which completed interviews were obtained for 4642 $(49.9 \%)$. We were unable to locate 2539 $(27.3 \%)$ of the respondents at the follow-up interview; and a further $608(6.5 \%)$ were not reached within 10 callback attempts. Also, 688 $(7.4 \%)$ refused, $149(1.6 \%)$ were unable to respond, $146(1.6 \%)$ were ineligible, and 538 $(5.7 \%)$ of the interviews were incomplete.

A total of $38.3 \%$ of those interviewed in 1992 were daily smokers in 1990 compared with $40.4 \%$ of 1992 non-respondents, which suggests that smoking status was not associated with failure to respond. Differences were observed on age (with 18- to 24-year-old respondents being less likely to be re-interviewed), on race/ethnicity (with Hispanics being less likely to be re-interviewed), and on education (with the lowest educated being less likely to be re-interviewed). We adjusted for these differences using standard weighting procedures. ${ }^{19,20}$

Respondents were given a base weight for the 1990 survey that reflected their probability of being selected for interview at that time. The base weight was then adjusted to reflect the probability that the respondent would be selected again in 1992. Finally, the weights were ratio adjusted to California population totals (age, gender, race/ethnicity, and edu- cation level) so that population inferences could be made. A complete description of the survey and weighting procedures is given elsewhere. ${ }^{19,20}$

\section{SURVEY QUESTIONS}

Essentially the same questionnaire was administered in 1992 as in 1990. All respondents were asked: 'Do you smoke cigarettes now?' For this analysis, respondents answering 'Yes' were considered to be current smokers, and smoking prevalence was simply the percentage answering 'Yes'. The next question asked was: 'Do you now smoke cigarettes every day or some days?' All daily smokers were asked: 'How many cigarettes on average do you smoke per day?' Those who reported smoking now, but who did not smoke every day in the past month, were asked: 'On how many of the past 30 days did you smoke cigarettes?' and 'During the past 30 days, on the days that you did smoke, about how many cigarettes did you usually smoke per day?' From these data, we computed average daily cigarette consumption by multiplying the number of days smoked by the number of cigarettes smoked on these days and dividing the result by 30 days. The population quit rate was the percentage of those who smoked in 1990 who did not smoke in 1992. Similarly, the population relapse/ uptake rate was the percentage of those who did not smoke in 1990 but did in 1992 .

All respondents were asked: 'Do you currently work outside your home?' and, if so: 'Do you work primarily indoors or outdoors?' Participants who worked indoors but outside the home were asked the following questions about smoking policies in their workplaces '(a) Does your employer have an official policy that restricts smoking in any way?'; '(b) Which of the following best describes the smoking policy for indoor public or common areas such as lobbies, rest rooms, and lunchrooms?'; and '(c) Which of the following best describes the policy for areas in which employees work?' Response choices for the last two questions included: 'Not allowed in any'; 'Allowed in some'; and 'Allowed in all'. A work area was said to be smoke-free if a policy existed and 'Not allowed in any' was the response to the third question.

\section{STATISTICS}

For means and percentages we have provided $95 \%$ confidence intervals. Variance estimates were derived using a variant of the jackknife procedure ${ }^{21}$ in which 51 replicate subsamples were formed from the full sample and sample weights were computed as outlined above. The deviation of the subsample values from the ful sample value allows variances to be estimated Satterthwaite's approximation, ${ }^{22,23}$ which is also based on the subsampling, was used to compute $\chi^{2}$ statistics.

We used logistic regression to model decrease in cigarette consumption as a function of workplace policy group, age, sex, education, and ethnicity. All workers who smoked in 


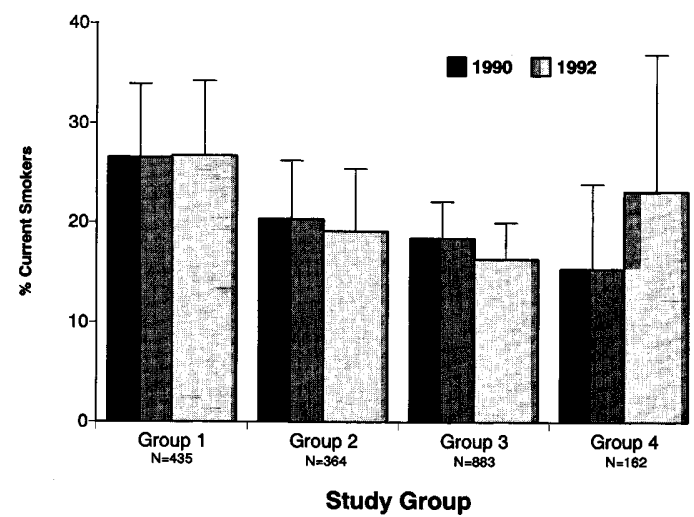

Smoking prevalence in 1990 and 1992 according to change in smoking policy restrictions in work areas. Groups are indoor workers employed in a smoke-free work area in: (1) neither 1990 nor 1992; (2) 1992 only; (3) 1990 and in 1992; or (4) 1990 only

either year were included. Decrease was coded as a binary variable; anyone whose daily consumption decreased by five cigarettes or more, or who quit, was coded 1 and all others were coded 0 . A similar analysis modelled a consumption increase of five cigarettes or more. Risk ratios were derived from the regression coefficients and $95 \%$ confidence intervals were computed using the jackknife procedure.

\section{Results}

WORKPLACE RESTRICTIONS AND SMOKING PREVALENCE IN 1990 AND 1992

Of the 4642 respondents in the longitudinal sample, 1844 were employed indoors, outside the home, in both survey years. A smoke-free work area was reported by $56.7 \%$ of these workers in 1990, and $67.6 \%$ in 1992. This group of indoor workers was classified according to whether they worked in a smokefree work area in: (1) neither 1990 nor 1992 ; (2) 1992 only; (3) 1990 and 1992; or (4) 1990 only. The figure shows the smoking prevalence for each of these groups in 1990 and 1992. Smoking prevalence decreased $(-11.4 \%$ change) from $18.4 \%$ (95\% CI 14.7 to $22.1 \%$ ) to $16.3 \%$ (95\% CI 12.6 to $20.0 \%$ ) among those working where work areas were smokefree in both years (group 3), and from $20.3 \%$ (95\% CI 14.4 to $26.2 \%$ ) to $19.1 \%$ (95\% CI 12.8 to $25.4 \%$ ) ( $-5.9 \%$ change), among those who worked in a workplace with smoke-free work areas in 1992 but not 1990 (group 2). For those working in workplaces that allowed smoking in work areas both years (group 1), prevalence was nearly the same for both years: $26.5 \%(95 \%$ CI 19.1 to $33.9 \%)$ in 1990 and $26.7 \%$ (95\% CI 20.4 to $33.0 \%$ ) in 1992 . However, for those who went from a workplace with smoke-free work areas to one without (group 4), prevalence increased from $15.3 \%$ (95\% CI 6.7 to $23.9 \%$ ) to $23.1 \%$ (95\% CI 9.3 to $36.9 \%)(+50.9 \%$ change). Because of the small sample sizes within the groups, we were not able to establish statistically that these changes were significantly different from zero or different for the four groups.

CHANGES IN SMOKING STATUS

Table 1 shows quit and relapse/uptake rates

Table 1 Quit and relapse rates

Table 2 Changes in smoking status for workplace policy change groups

\begin{tabular}{|c|c|c|c|c|}
\hline \multirow[b]{2}{*}{ Work area policy } & \multirow[b]{2}{*}{ No } & \multicolumn{3}{|c|}{ Smoking status* } \\
\hline & & $\begin{array}{l}\text { Smoked both } \\
\text { years }\end{array}$ & $\begin{array}{l}\text { Smoked 1990/ } \\
\text { quit } 1992\end{array}$ & $\begin{array}{c}\text { Not smoked } 1990 / \\
\text { smoked } 1992\end{array}$ \\
\hline \multicolumn{5}{|l|}{ Group 1} \\
\hline $\begin{array}{l}\text { Not smoke-free } 1990 \\
\text { Not smoke-free } 1992\end{array}$ & 232 & $82.7(9.1)$ & $8.4(4.3)$ & $8.9(7.7)$ \\
\hline \multicolumn{5}{|l|}{ Group 2} \\
\hline $\begin{array}{l}\text { Not smoke-free } 1990 \\
\text { Smoke-free } 1992\end{array}$ & 166 & $72.0(12.7)$ & $16.7(8.3)$ & $11.3(13.1)$ \\
\hline \multicolumn{5}{|l|}{ Group 3} \\
\hline $\begin{array}{l}\text { Smoke-free } 1990 \\
\text { Smoke-free } 1992\end{array}$ & 383 & $71.0(9.4)$ & $19.7(9.7)$ & $9.3(3.7)$ \\
\hline \multicolumn{5}{|l|}{ Group 4} \\
\hline $\begin{array}{l}\text { Smoke-free } 1990 \\
\text { Not smoke-free } 1992\end{array}$ & 79 & $54.6(27.3)$ & $7.0(6.2)$ & $38.4(30.0)$ \\
\hline
\end{tabular}

^Entries are weighted percentages ( $95 \%$ confidence intervals).

Overall $\mathrm{Rao}^{22,23} \chi^{2}$ for association of change in workplace policy with change in smoking status, $\mathrm{p}<0.06$. for the different workplace policy groups. The quit rate was about twice as high in the two groups which were smoke-free in 1992 compared with the groups that allowed smoking in the workplace in 1992. The relapse/uptake rate was lowest among workers whose work area was smoke-free in both years and highest among workers whose work area was smokefree in 1990 but not smoke-free in 1992 . Because of wide confidence intervals, however, the rates are not statistically different among the groups where work area policy changed.

Looking only at those individuals who were identified as current smokers in 1990 or in 1992 allows changes in smoking behaviour to be examined as a function of change in 
Table 3 Changes in cigarette consumption for workplace policy change groups

\begin{tabular}{|c|c|c|c|c|c|}
\hline \multirow[b]{2}{*}{5} & \multirow[b]{2}{*}{ Work area policy } & \multirow[b]{2}{*}{ No } & \multicolumn{3}{|c|}{ Cigarettes/day ${ }^{\star}$} \\
\hline & & & 1990 & 1992 & Change \\
\hline 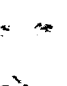 & $\begin{array}{l}\text { Group } 1 \\
\text { Not smoke-free } 1990 \\
\text { Not smoke-free } 1992\end{array}$ & 232 & $14.86(2.73)$ & $14.41(2.47)$ & $-0.45(1.42)$ \\
\hline$\Rightarrow$ & $\begin{array}{l}\text { Group } 2 \\
\text { Not smoke-free } 1990 \\
\text { Smoke-free } 1992\end{array}$ & 166 & $14.51(3.27)$ & $13.11(2.53)$ & $-1.41(2.16)$ \\
\hline 2 & $\begin{array}{l}\text { Group 3 } \\
\text { Smoke-free } 1990 \\
\text { Smoke-free } 1992\end{array}$ & 383 & $12.98(1.57)$ & $12.08(1.83)$ & $-0.90(0.89)$ \\
\hline$=2$ & $\begin{array}{l}\text { Group } 4 \\
\text { Smoke-free } 1990 \\
\text { Not smoke-free } 1992\end{array}$ & 79 & $6.63(3.59)$ & $10.98(7.24)$ & $4.35(7.91)$ \\
\hline
\end{tabular}

$\star$ Entries are means $(95 \%$ confidence intervals). When the confidence interval for change overlaps zero, the change is not significant. workplace policy. Table 2 shows the percentages of the respondents in each of the workplace change groups who smoked in both years, in 1990 but not in 1992, and not in 1990 but in 1992. The highest percentage of those smoking in both survey years $82.7 \%$ (95\% CI 73.6 to $91.8 \%$ )) was in the subgroup working in workplaces that allowed smoking in work areas in both years. The percentage quitting smoking was highest $(19.7 \%$ (95\% CI 10.0 to $29.4 \%)$ ) for those in workplaces with smokefree work areas in both years, but almost as high (16.7\% (95\% CI 8.4 to $25.0 \%)$ ) for those whose work area became smoke-free in 1992. Each group showed some initiation or relapse, but the percentage initiating or relapsing to smoking was much higher for those who worked in a workplace with smoke-free work areas in 1990 but not in 1992. The $\chi^{2}$ statistic for this table was $p<0.060$, suggesting a possible relationship between changes in workplace smoking restrictions and changes in smoking status.

\section{CHANGES IN CIGARETTE CONSUMPTION}

Table 3 gives the average daily cigarette consumption for both years reported by those who smoked in either 1990 or 1992 and the difference in reported consumption (19921990). Respondents who smoked in neither year were excluded from the analysis. Those who smoked in only one year were regarded as having a zero consumption level for the survey year in which they were not smoking. In 1990, consumption tended to be higher in workplaces allowing smoking in work areas compared with those that had smoke-free work areas. Although consumption decreased among those in work areas that allowed smoking in both years, the drop was greater among those working in smoke-free work areas in both years or changing from a work situation lacking smoke-free work areas to one where the work areas were smoke-free. For those remaining in a smokefree work area, the $95 \%$ confidence intervals do not overlap zero; however, because of the small sample sizes, the changes observed in the other groups are not statistically significant.

\section{MULTIVARIATE ANALYSIS}

Because changes in smoking status and consumption that have been attributed to changes in workplace smoking policies may, in fact, result from other confounding variables, a multivariate analysis was performed, modelling decrease in cigarette consumption as a function of workplace policy group, age, sex, education, and ethnicity. A similar analysis modelled increase in cigarette consumption.

The first analysis modelling decrease in consumption showed that those who moved from a smoke-free work area to an unrestricted work area were much less likely than those whose work area remained unrestricted in both years to decrease consumption $(p<0.02$; Table 4). Also, Asians were significantly less likely than white respondents to decrease consumption $(p<0.05)$. The second analysis modelling increase in consumption showed Hispanics were less likely than white respondents to increase consumption $(p<0.001)$. Consumption increase was not significantly related to workplace policy, although workers who moved from a smoke-free work area in 1990 to a work area allowing smoking in 1992 had twice the odds of increasing consumption compared with those whose work areas permitted smoking in both years.

Table 4 Results of logistic regression

\begin{tabular}{|c|c|c|c|c|c|c|}
\hline \multirow[b]{2}{*}{ Variable } & \multicolumn{6}{|c|}{ Odds for consumption change } \\
\hline & Decrease & $95 \% C I$ & $p$ & Increase & $95 \% C I$ & $p$ \\
\hline \multicolumn{7}{|l|}{ Age } \\
\hline $18-24$ & 1.00 & & & 1.00 & & \\
\hline $25-44$ & 1.73 & $0.73-4.12$ & 0.21 & 0.72 & $0.21-2.49$ & 0.60 \\
\hline $\begin{array}{l}\geqslant 45 \\
\text { Male }\end{array}$ & 1.29 & $0.57-2.88$ & 0.53 & 0.74 & $0.26-2.07$ & 0.56 \\
\hline $\begin{array}{l}\text { Male } \\
\text { Female }\end{array}$ & 1.00 & & & 1.00 & 045,24 & \\
\hline $\begin{array}{l}\text { Female } \\
\text { Education }\end{array}$ & 1.12 & \multicolumn{3}{|c|}{ Education } & & 0.35 \\
\hline$<12$ years & 1.00 & & & 1.00 & & \\
\hline 12 years & 0.83 & $0.35-1.98$ & 0.67 & 0.60 & $0.13-2.68$ & 0.50 \\
\hline$>12$ years & 0.88 & $0.42-1.86$ & 0.73 & 0.65 & $0.17-2.48$ & 0.52 \\
\hline White & 1.00 & & & 1.00 & & \\
\hline Black & 0.88 & $0.30-2.55$ & 0.80 & 1.15 & $0.43-3.05$ & 0.78 \\
\hline Hispanic & 0.76 & $0.28-2.07$ & 0.59 & 0.11 & $0.03-0.40$ & 0.001 \\
\hline Asian/other & 0.43 & $0.18-1.00$ & 0.05 & 1.88 & $0.49-7.24$ & 0.35 \\
\hline Not smoke-free 1990 and 1992 & 1.00 & & & 1.00 & & \\
\hline $\begin{array}{l}\text { Smoke-free } 1990 \text { and } 1992 \\
\end{array}$ & 1.06 & $\begin{array}{l}0.55-2.03 \\
0.58-2.85\end{array}$ & $\begin{array}{l}0.86 \\
0.53\end{array}$ & $\begin{array}{l}0.95 \\
1.33\end{array}$ & $\begin{array}{l}0.53-1.69 \\
0.57-3.09\end{array}$ & $\begin{array}{l}0.85 \\
0.48\end{array}$ \\
\hline $\begin{array}{l}\text { Not smoke-tree } 1990 / \text { smoke-free } 1992 \\
\text { Smoke-free } 1990 / \text { not smoke-free } 1992\end{array}$ & 0.30 & $0.12-0.79$ & 0.02 & 2.04 & $0.46-9.15$ & 0.34 \\
\hline
\end{tabular}

$\mathrm{CI}=$ Confidence interval. 


\section{Discussion}

Our data demonstrate a lower smoking prevalence in those groups whose work area was smoke-free compared with those with no smoking restrictions in the work area. These findings further strengthen our previous observation that more comprehensive smoking policies are associated with lower rates of smoking among California indoor workers. ${ }^{5}$ Although the validity of self-report data regarding workplace smoking policies needs further study, a previous study found that California workers who reported the presence of a smoke-free workplace were likely to be covered by a strong local workplace smoking ordinance. ${ }^{24}$

Smokers appear to have modified their behaviour when a smoking policy was maintained in the work area in both years surveyed. We observed a percentage decrease in smoking prevalence of $11 \%$ when a work area smoking ban was maintained during both years, compared with a smaller percentage reduction in prevalence $(6 \%)$ among those whose work area had no smoking restrictions in 1990 but restricted smoking in 1992. Although these individual effects were not significant, the analysis of overall change in smoking status (Table 2) suggested an association $(\mathrm{p}<0.06)$. Also, these trends are consistent with others findings which suggest that smoking prevalence may decrease over a considerable time period in response to policy changes. ${ }^{14,15}$

The largest decrease in cigarette consumption was found for workers whose workplace policy changed from not requiring a smokefree work area in 1990, to designating work areas smoke-free in 1992. Conversely, the multivariate analysis indicated that those who moved from a smoke-free work area to one allowing smoking were significantly less likely to decrease consumption. Previous studies have found that reductions in cigarette consumption may be a more proximal or immediate effect of the introduction of smoking bans in work areas. ${ }^{10-12}$ Maintaining a lower level of cigarette consumption may be a helpful precursor to the achievement of eventual smoking cessation. ${ }^{7,10}$ Thus, the increasing trends toward smoke-free workplaces should benefit the health of smokers by effecting changes in smoking behaviour. ${ }^{25,26}$

Smoking behaviour was more stable among those employed in a workplace without a work area smoking ban in 1990 and 1992. Slight decreases in cigarette consumption were observed, however, which likely parallel those in the general population; both prevalence and consumption have declined in California in the last several years. ${ }^{18}$

In this study, we were able to explore changes in smoking behaviour when employees moved from a work area with smoking restrictions to one without restrictions. These individuals most likely changed their employment between 1990 and 1992. It is improbable that a workplace would rescind a work area smoking policy given the potential legal implications of the Environmental Protection Agency report, which classified ETS as a proven human carcinogen. ${ }^{2}$ This group was younger (under 25 years of age) and consisted of a much higher fraction of Hispanics than the other workplace policy groups. Hispanics are often occasional smokers and they, as well as younger adults, have a low smoking prevalence. ${ }^{27,28}$ Hispanics were shown in the multivariate analysis to be unlikely to increase their consumption; their overrepresentation in the group moving away from smoke-free work areas might mask a consumption increase among other ethnic groups. It is possible that some workers who moved away from a smoke-free work area changed jobs because of dislike for the policy. The California economy experienced considerable turbulence during this period, however, which probably disproportionally affected younger and minority workers. Thus, worker insecurity is a more probable reason for job change than smoking policy.

Our findings suggest that both smoking prevalence and cigarette consumption increased among employees who reported working under a smoking ban in their work area in 1990 but not in 1992. This group reported a marked percentage increase $(50.9 \%)$ in smoking prevalence over the two years surveyed, and an increase in cigarette consumption among those reporting smoking in either years of about four cigarettes per day. Additionally, $38 \%$ of these workers did not report smoking in 1990, but reported smoking in 1992. Although these data are suggestive of relapse to smoking when changing from a workplace with smoke-free work areas to one without, we cannot draw definite conclusions as this is a small subsample $(n=79)$. Future studies are needed to further examine the possible impact of reduced workplace smoking restrictions on smoking behaviour.

Our survey was designed to allow us to examine changes in overall smoking behaviour in California during a two-year follow-up period. For this study, the necessity to restrict the analyses to indoor workers who were employed outside the home during both survey years diminished our ability to show statistical significance. The consistent trends in the data, however, support the benefit of workplace smoking policies in encouraging changes in smoking behaviour when such policies are instituted and maintained. Further, the evidence suggests that prevalence rates and consumption may increase when workers move from a workplace with a smoke-free work area to a workplace with no such restrictions.

This study was supported by contracts $89-97872$ and 92-16010 from the California Department of Health Services, Tobacco Control Section, Sacramento.

1 Rigotti NA, Pashos CL. No-smoking laws in the United States: an analysis of state and city actions to limi smoking in public places and workplaces. $f A M A$ 1991; 266: 3162-7.

2 US Environmental Protection Agency. Respiratory health effects of passive smoking: lung cancer and other disorders. Washington, DC: Office of Research and Developmen and Office of Air and Radiation, 1992. (Publication No EPA $/ 600 / 6-90-006 \mathrm{~F}$.

3 Doll R, Peto R. The causes of cancer: quantitative estimates of avoidable risks of cancer in the United States today. $\mathcal{F}$ Natl Cancer Inst 1981; 66: 1191-308.

4 US Department of Health and Human Services. The health benefits of smoking cessation. A report of the Surgeon

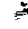

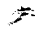

$=$

2

$\$$

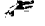

4

8

-

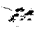

3

3

$\div$

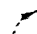

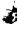

3

$-$

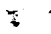

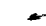

$\therefore$

$-$

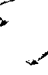

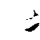

,

,

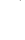

$-$

$x$ 
General, 1990. Rockville, Maryland: Public Health Service, Centers for Disease Control, Office on Smoking and Health, 1990. (DHHS Publication No (CDC) $90-8416$.)

5 Woodruff TJ, Rosbrook B, Pierce J, Glantz SA. Lower levels of cigarette consumption found in smoke-free workplaces in California. Arch Intern Med 1993; 153: 1485-93.

6 Becker DM, Conner HF, Waranch HR, Stillman F, Pennington L, Lees PS, et al. The impact of a total ban on smoking in the John Hopkins Children's Center. on smoking in the John $1989 ; 262: 799-802$.

7 Borland $\mathrm{R}$, Owen $\mathrm{N}$, Hocking $\mathrm{B}$. Changes in smoking behaviour after a total workplace smoking ban. Aust $\mathscr{F}$ Public Health 1991 ; 15: 130-4.

8 Hocking B, Borland R, Owen N, Kemp G. A total ban on workplace smoking is acceptable and effective. $\mathcal{F}$ Occup Med 1991; 33: 163-7.

9 Millar WJ. Evaluation of the impact of smoking restrictions in a government work setting. Can $\mathcal{F}$ Public Health 1988; 79: 379-82.

10 Borland R, Chapman S, Owen N, Hill D. Effects of workplace smoking bans on cigarette consumption. $A m \mathcal{F}$ workplic Health $1990 ; 80: 178-80$.

11 Hudzinski LG, Frohlich ED. One-year longitudinal study of a no-smoking policy in a medical institution. study of a no-smoking policy

12 Jeffery RW, Kelder SH, Forster JL, French SA, Lando HA, Baxter JE. Restrictive smoking policies in the workplace: effects on smoking prevalence and cigarette consumption. Prev Med 1994; 23: 78-82.

13 Biener L, Abrams DB, Follick MJ, Dean L. A comparative evaluation of a restrictive smoking policy in a general hospital. Am $\mathcal{F}$ Public Health 1989; 79: 192-5.

14 Offord KP, Hurt RD, Berge KG, Frusti DK, Schmidt L. Effects of the implementation of a smoke-free policy in a medical center. Chest 1992; 102: 1531-6.

15 Stillman FA, Becker DM, Swank RT, et al. Ending smoking at the Johns Hopkins Medical Institutions: an evaluation of smoking prevalence and indoor air pollution. $\mathcal{F} A M A 1990 ; 264$ : 1565-9.
16 Waksberg J. Sampling methods for random digit dialing. $\mathcal{F}$ Am Stat Assoc 1978; 73: 40-6.

17 Waksberg J. Efficiency of alternative methods of establishing cluster sizes in RDD sampling. Westat Technical Note (unpublished) 1984 Dec 17.

18 Pierce JP, Evans N, Farkas AF, et al. Tobacco use in California. An evaluation of the Tobacco Control Program, 1989-1993. La Jolla, California: University of California San Diego; 1994.

19 Pierce JP, Cavin SW, Macky C, et al. Technical report on analytic methods and approaches used in the 1992 California Tobacco Survey analysis. Sacramento, Cali-

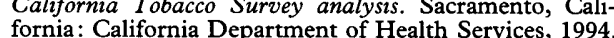
20 Pierce JP, Goodman J, Gilpin E, Berry C. Technical report ierce JP, Goodman J, Gilpin E, Berry C. Technical report of analytic methods and approaches used in the tobacco use in California, 1990-1991 Report. Sacramento, California: California Department of Health Services, 1992.

21 Efron B. The jackknife, the bootstrap and other resampling plans. CBMS Regional Conference Series in Applied Mathematics, 38. Philadelphia: Society for Industrial and Applizu Mathematics, 1982.

22 Rao JNK, Scott AJ. The analysis of categorical data from complex sample surveys: chi-square tests for goodness of fit and independence in two-way tables. $7 \mathrm{Am}$ Stat Assoc 1981; 76: 221-30.

23 Rao JNK, Scott AJ. On chi-squared tests for multiway contingency tables with cell proportions estimated from survey data. Ann Stat $1984 ; 12$ : 45-60.

24 Pierce JP, Shanks TG, Pertschuk M, et al. Do smoking ordinances protect non-smokers from environmental tobacco smoke at work? Tobacco Control 1994; 3: 15-20. 25 Fielding JE. Smoking control at the workplace. Annu Rev Public Health 1991; 12: 209-234

26 Bureau of National Affairs. Bulletin to management: smoking in the workplace 1991, SHRM- BNA Survey No 55, 1-2.

27 Burns DM, Pierce JP. Tobacco use in California 1990-1991. Sacramento, California : California Department of Health Services, 1992.

28 Evans NJ, Gilpin E, Pierce JP, et al. Occasional smoking among adults: evidence from the California Tobacco Survey. Tobacco Control 1992; 1: 169-75. 